\title{
Studi Fenomenologi: Pengalaman Spiritualitas Klien Perempuan Dengan Chronic Kidney Desease (CKD) Yang Menjalani Hemodialisys Di RSUD Dr. H. Koesnadi Bondowoso.
}

\author{
Setiyo Adi Nugroho', Handono Fatkhur Rohman², \\ Mamlu'ul hasanah ${ }^{3}$. \\ 1Universitas Nurul Jadid, email: setiyo666@gmail,com \\ 2Universitas Nurul Jadid. \\ 3Universitas Nurul Jadid.
}

\section{ABSTRACT}

Aspect of spirituality is one of the important issues in the care of female clients who undergo hemodialisys. The purpose of this study to explore more deeply about the meaning of the spirituality of female clients who undergo hemodialisys. This research plan uses qualitative with descriptive phenomenology approach. The study derives five themes: (1) relationship with God, (2) relationships with oneself, (3) relationships with others, (4) originators and inhibitors, and (5) client expectations. A total of 6 female participants by using purposive sampling. Data were collected by in-depth interviews and observations. Data analysis using selective and highlighting approach (the selective or highlighting approach). The results of this study participants changed in terms of worship is an increase in terms of worship. To that end, nurses can provide appropriate nursing interventions to help clients.

Keywords : Chronic Kidney Disease, Hemodialysis, Spirituality, and Women. 


\section{Abstrak}

Aspek spiritualitas merupakan salah satu isu penting dalam asuhan klien perempuan yang menjalani hemodialisys. Tujuan penelitian ini untuk menggali lebih dalam tentang makna spiritualitas klien perempuan yang menjalani hemodialisys. Rencana penelitian ini menggunakan kualitatif dengan pendekatan fenomenologi deskriptif. Penelitian ini memperoleh lima tema yaitu (1) hubungan dengan Tuhan, (2) hubungan dengan diri sendiri, (3) hubungan dengan orang lain, (4) pencetus dan penghambat, dan (5) harapan klien. Sebanyak 6 partisipan perempuan dengan mengggunakan purposive sampling. Data dikumpulkan dengan wawancara mendalam dan observasi. Analisis data menggunakan selektif dan focusing (the selective or highlighting approach). Hasil penelitian ini partisipan mengalami perubahan dalam hal ibadah yaitu peningkatan dalam hal ibadah. Untuk itu, perawat dapat memberikan intervensi keperawatan yang tepat untuk membantu klien.

Kata Kunci: Chronic Kidney Desease, Hemodialisys, Spiritualitas, dan Perempuan 
Pendahuluan

Penyakit

Cronic

Kidney Desease (CKD) menjadi masalah dalam kesehatan dan memiliki dampak yang panjang bagi kehidupan seperti gangguan kesehatan fisiologis, psikologis, sosial dan spiritual (Morton, Tong, Howard, Snelling, \& Webster, 2010).

Pada tahun 2009 di Amerika

Serikat sebanyak 570.000 orang menjalani terapi hemodialisys atau transplantasi ginjal, sementara di Inggris diperkirakan sekitar 140.000 orang (AJ1 et al., 2012). Sedangkan di Indonesia Pada tahun 2015, terdata dari mesin hemodialisys dengan total 4.898, proporsi di provinsi di Jawa Timur sebanyak $11 \%$, (Kemenkes RI, 2013).

Dalam penelitian Cleary (2005) Timmers et al (2008) menyatakan bahwa klien CKD yang menjalani hemodialisys banyak mengalami perubahan dalam kualitas hidup baik dari aspek psikologis, emosional, dan fisik seseorang (Cleary, 2005; Timmers et al., 2008). Merasakan kehilangan kemampuan fisik dan kognitif yang akhirnya membawa klien pada kesedihan dan keputusasaan sehingga menyebabkan

pemutusan

hemodialisys, perilaku ini dianggap sebagai pemikiran bunuh diri, bunuh diri disebabkan akibat kegagalan mengatasi depresi dialisis (Kurella \& Chertow, 2005).

Gangguan mental untuk nonpsikotik seperti depresi dapat diatasi dengan menggunakan spiritual (Wicaksana, 2008). Spiritualitas sangatlah penting bagi keberadaan seseorang, spiritualitas sebagai komponen kebutuhan manusia yang dapat memberikan makna dalam kehidupan, sebagai 
ketenangan dan menjadi mekanisme koping dalam mengadapi penyakit kronis (Ruth A. Tanyi, 2003).

Dalam penelitian eig-Ferrer et al (2012) menyatakan bahwa tingkat spiritualitas perempuan lebih tinggi dari pada laki-laki (ReigFerrer et al., 2012). Karena perempuan dalam hal menafsirkan perasaan stress dan penyesuaian dalam kehidupan yang baru akan berbeda dibandingkan laki-laki (Taylor, E et al., 2000). Meneliti

pengalaman spiritual perempuan yang sedang menjalani hemodialisys sangatlah penting dengan beberapa alasan, yaitu pertama perempuan setelah terkena CKD maka perempuan tersebut harus ke rumah sakit 2-3 kali per minggu secara rutin, mereka perlu beradaptasi dengan kehidupan barunya. Alasan kedua dengan pengobatan yang panjang maka akan muncul gangguan kesehatan seperti masalah fisiologi, psikologis, sosial dan spiritual.

Penelitian ini di rumuskan oleh dua pertanyaan, yaitu

Spiritualitas seperti apa yang klien lakukan, (2) bagaimana pengalaman spiritualistas klien perempuan selama menjalani hemodialisa di RS.Koesnadi Bondowoso ? dengan tujuan sebagai berikut: (1) Teridentifikasinya informasi tentang pengalaman spiritual klien perempuan yang menjalani hemodialisys dengan Tuhan; Teridentifikasinya informasi tentang pengalaman spiritual klien perempuan yang menjalani hemodialisys dengan diri sendiri; (3) Teridentifikasinya informasi tentang pengalaman spiritual klien perempuan yang menjalani hemodialisys dengan orang lain; Teridentifikasinya 
Setiyo Adi Nugroho: Pengalaman Spiritualitas

informasi tentang faktor pencetus

dan

penghambat

spiritualitas pengalaman klien perempuan yang menjalani hemodialisys; (5) Teridentifikasinya informasi tentang harapan perempuan klien penyakit chronic kidney desease (CKD).

\section{Metode}

Penelitian ini menggunakan metode kualitatif dengan

pendekatan fonomenologis.

Rekrutmen partisipan dilakukan dengan cara purposive sampling (Afiyanti \& Rachmawati, 2014). Terdapat 6 partisipan yang tersaturasi dan sesuai dengan kriteria penelitian. Data diperoleh dengan teknik wawancara terbuka. Dalam melakukan pengumpulan data, peneliti merupakan instrumen utama dalam penelitian ini, selain itu peneliti juga menggunakan alat bantu berupa format pengumpulan data berisi data biografi dan status medis, pertanyaan-pertanyaan tertulis sebagai pedoman untuk wawancara, buku catatan dan alat tulis. Analisis data dilakukan setiap selesai mengumpulkan data dari satu partisipan. Hasil analisis dapat mengarahkan pada proses selanjutnya. Transkrip-transkrip dari hasil wawancara dan catatan lapangan (field notes) yang telah dibuat peneliti secara bersamaan di analisis. Teknik analisis spesifik dengan menggunakan pendekatan analisis selektif dan fokusing (the selective or highlighting approach). Sebagai langkah terakhir, peneliti mempersiapkan tematema esensial yang merupakan suatu deskripsi paling terakhir dari fenomena yang terjadi (an exhaustive 
description of the phenomenom) (Afiyanti \& Rachmawati, 2014).

\section{Hasil Penelitian}

Penelitian ini mendapatkan 5 Tema, yaitu: (1) Hubungan dengan Tuhan; (2) Hubungan dengan diri sendiri; (3) Hubungan dengan orang lain; (4) Faktor pencetus dan penghambat spiritualitas;

Harapan klien.

Tema 1 Hubungan Klien Perempuan yang menjalani Hemodialisis dengan Tuhan terdiri dari satu sub tema yaitu ibadah, dan 4 kategori yaitu: sholat, dzikir, mengaji dan solawatan.

Tema 2 hubungan dengan diri sendiri terdiri dari satu tema yaitu respon berduka klien saat harus menjalani hemodilalisys terdiri dari 5 kategorik. Diantaranya tahap pengingkaran, tahap marah, tahap tawarmenawar, tahap depresi, tahap penerimaan.
Tema 3 Hubungan dengan orang lain terdiri dari satu sub tema yaitu sumber kekuatan atau penyembuh serta tiga kategori keluarga, teman, dan saudara.

Tema 4 yaitu Faktor pencetus dan faktor penghambat bagi klien perempuan yang menjalani hemodialisys terdiri masing-masing satu tema, untuk faktor pencetus dengan tema karena tindakan dan menghasilkan dua kategorik yaitu lemas dan pusing (sakit kepala).

Tema 5 tema harapan klien perempuan yang menjalani hemodilaisys seperti terlihat dengan adanya satu sub tema yaitu harapan akan kesembuhan penyakit dan dua kategorik sembuh dan lebih sembuh.

\section{Pembahasan}

Hasil penelitian ini menemukan makna baru yang dirasakan oleh partisipan setelah 
menjalani hemodialisys yaitu merasa lebih dekat kepada Tuhan dengan alasan partisipan takut akan kematian, takut akan meninggalkan keluarga yang tersayang dan merasa menyesal akan kesalahan di masa lampau.

Pada penelitian ini di dapatkan hasil bahwa lebih mendekatkan diri kepada Tuhan di awali dengan menyadari kesalahan yang di perbuat, kemudian di realisasikan dengan keinginan untuk bertaubat kepada Tuhan. Sejalan dengan Betsy \& Eric (2000) melaporkan bahwa untuk menemukan arti baru dan bertahan hidup ditandai dengan terjadinya banyak kesalahan, konflik dan perasaan bersalah (Betsy \& Eric, 2000).

$$
\text { Potter }
$$

mengatakan ada empat hal yang diakui sebagai kebutuhan spiritual yang salah satunya adalah proses mencari makna baru dalam kehidupan. Proses mencari makna baru dalam kehidupan merupakan proses yang unik dan bukanlah hal yang mudah karena akan menimbulkan stress dan perasaan marah, perasaan menyesal atau perasaan bersalah (Potter \& Perry, 2005).

Hasil penelitian Patien, Preposi, Paolo, dan Hikmet (2016) menyatakan bahwa spiritualitas sangat penting untuk meningkatkan kesehatan bagi klien homodialisys, karena dengan cara pendekatan holistik mampu untuk mendorong klien meningkatkan

kesehatannya (Patients, Preposi, Paolo, \& Hikmet, 2016). Sejalan dalam penelitian Bussing \& Surzykiewicz (2015) Menyatakan bahwa spiritualitas atau religius menjadi indikator penting dalam mengatasi masalah psikologis klien (Büssing \& Surzykiewicz, 2015). 
Berdasarkan hasil penelitian pada klien perempuan yang menjalani hemodialisys. Banyak partisipann mengungkapkan bahwa makna kehidupan mereka akan lebih di manfaatkan untuk kedepannya. Partisipan menyesali akan perbuatannya dahulu yang pernah berbuat salah partisipan mulai terdiagnosa sampai menjalani himodialysis, pola ibadah atau spritualitas mereka semakin meningkat atau semakin mendekatkan diri kepada Tuhan, alasannnya karna takut akan kematian dan akan meninggalkan keluarga.

$$
\text { Pada }
$$

tema

hubungan dengan diri sendiri bagi klien perempuan yang menjalani hemodialisys menghasilkan satu tema yaitu respon berduka dimana banyak persepsi klien mengatakan bahwa ikhlas dan sudah menerima dengan keadaanya.
Hasil penelitian klien perempuan yang menjalani hemodialisys, berdasarkan pernyataan partisipan banyak mengatakan ikhlas dengan apa yang menimpanya sekarang. Menerima atas apa yang terjadi, semua itu karna partisipan sudah menjalani hemodialisys di atas 1 tahun, dan telah melewati tahap pengingkaran hingga sampai sekarang tahap penerimaan.

Pada respon berduka dengan tahap penerimaan dimana berkaitan dengan reorganisasi perasaan kehilangan. Pemikiran yang selalu berpusat pada objek yang hilang akan mulai berkurang atau hilang. Individu telah menerima kenyataan kehilangan yang di alaminya dan mulai memandang kedepan (Hidayat, 2013).

Penelitian Armiyati \& Rahayu (2008) menyatakan bahwa ada hubungan antara lama 
menjalani hemodialisys yaitu dimana semakin lama menjalani hemodialisys maka akan melewati tahap demi tahap sampai klien tersebut sampai pada tahap peneriamaan dengan koping klien (Armiyati \& Rahayu, 2008).

Dukungan

terhadap

setelah partisipan menjalani hemodialisys sebagian besar adalah oleh keluarga dalam hal ini pasangan hidup (suami atau istri ), dan orang tua. Teman- teman dekat yang berasal dari lingkungan yang sama juga turud memberikan dukungan. Hal ini di dukung oleh hasil penelitian Molefe \& Duma (2009) pada perempuan di Botswana yang mengalami penyakit kronis bahwa dukungan dari orang lain sangat berarti, dukungan yang dapat di berikan adalah dukungan emosional dan dukungan fisik (Molefe \& Duma, 2009).
Tarakheswar, Pearce, Sikkema (2005) dalam penelitiannya tentang perkembangan dan implementasi kelompok terhadap spiritual koping pada penderita hemodialisys mengatakan bahwa refleksi dari kehidupan spiritual yaitu dengan mendapatkan hubungan dari keluarga atau anak, dan keluarga sebagai sumber konflik atau ketegangan

(Tarakheswar \& Pearce, 2005).

Harapan untuk hidup lebih baik di hari depan pada klien perempuan yang menjalani hemodialisys yaitu harapan untuk kesembuhan terhadap penyakit. Sebagian besar partisipan mengungkapkan

harapannya adalah mencari pekerjaan yang baru dan tetap melakukan aktivitas seperti biasa sperti diungkapkan oleh partisipan yang mempunyai cacat fisik. Bagi mereka cacat 


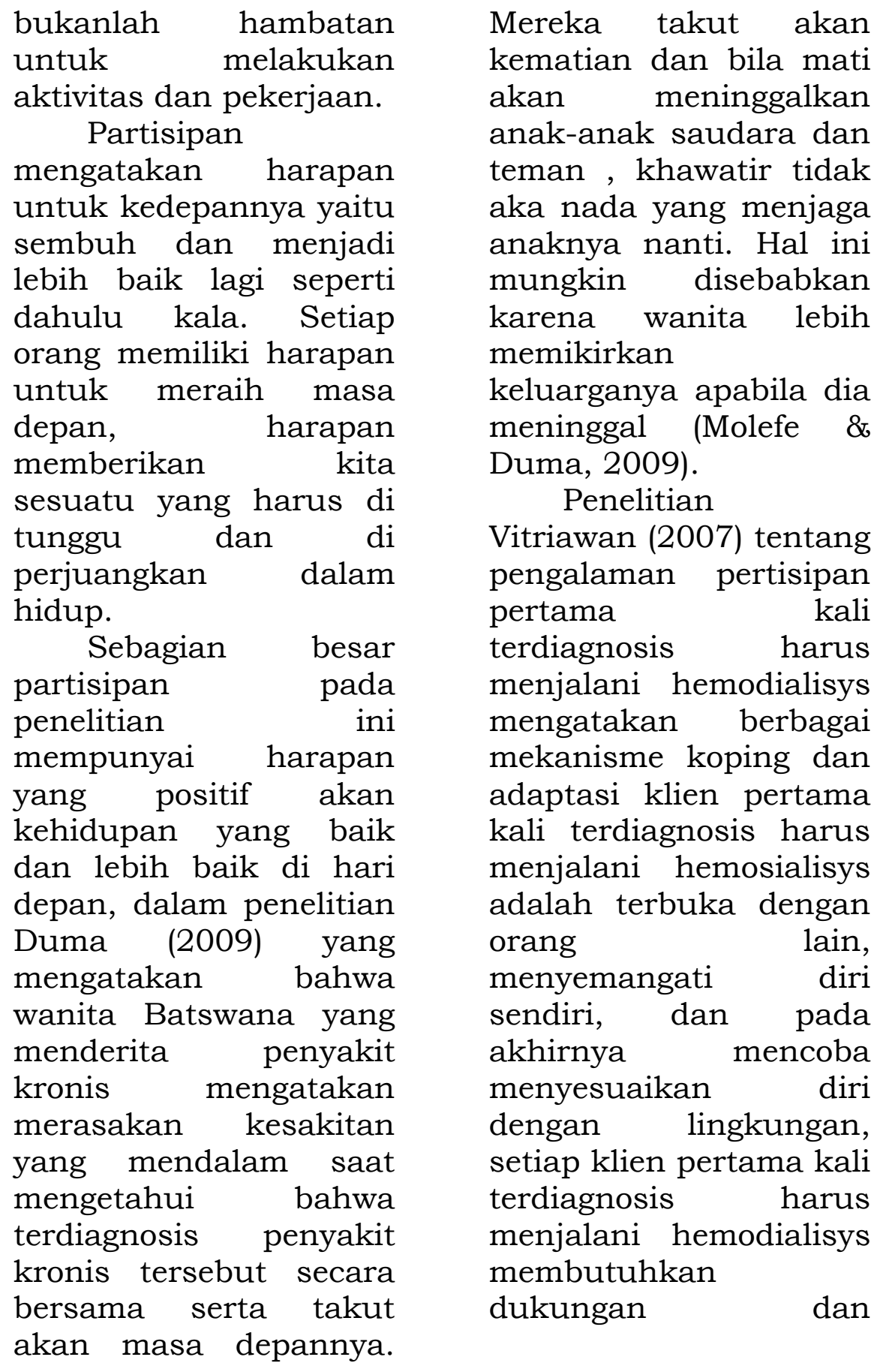


Setiyo Adi Nugroho: Pengalaman Spiritualitas

lingkungan sekitarnya (Vitriawan, 2007).

\section{Simpulan}

Penderita Cronic Kidney Desease (CKD) yang menjalani hemodialisis mempunyai banyak masalah dalam kehidupannya, diantaranya fisiologis, psikologis, sosial dan spiritual. berdasarkan gender perempuan yang menderita CKD dengan hemodialisis mudah lebih mengalami depresi, hal ini karenakan perempuan lebih manafsirkan perasaan stress dan penyesuaian dalam kehidupan yang baru dibanding laki-laki. Manajemen spritual menjadi pentng untuk meningkatkan kualitas pasien. Untuk itu, perlu penelitian lebih lanjut terkait manajemen spritual dlam meningkatkan kualitias hidup pasien perempuan yang CKD dengan hemodialisis.

\section{Daftar Pustaka}

Afiyanti, Y., \& Rachmawati. (2014). Metodelogi Penelitian Kualitatif dalam Keperawatan (II). Jakarta: PT RajaGrafindo Persada.

AJ 1, C., RN, F., Chavers, Gilbertson, Herzog, Johansen, Agodoa. (2012). United States Renal Data System 2011 Annual Data Report: Atlas of chronic kidney disease \& end-stage renal disease in the United States. Retrieved from

https://www.ncbi.n1 m.nih.gov/pubmed/ 22177944

Armiyati, Y., \& Rahayu, desi ariyana. (2008). Faktor yang Berkorelasi terhadap Mekanisme Koping Pasien CKD yang Menjalani

Hemodialisys di RSUD Kota Semarang (Correlating factors 
of coping mechanism on CKD patients undergoing

Hemodialysis

in

RSUD

Kota

Semarang).

Betsy, L., \& Eric, R. (2000).

The

dimensionality of stigma :

comparison of its impact on the self of persons with HIV /

A. Journal of health and social behavior , 41(1), 50-67.

Büssing,

A., $\quad \&$

Surzykiewicz, J. (2015).

Interpretation of Illness in Patients with

Chronic

Diseases from

Poland and Their

Associations with

Spirituality, Life

Satisfaction, and

Escape from

Illness-Results from

a Cross Sectional Study, 763-780.

https://doi.org/10.3 390/re16030763

Cleary, J. J. D. (2005). Quality of life of patients on haemodialysis for end-stage renal

disease. Journal of

Advanced Nursing,

51(6), 577-586.

Retrieved from

http://onlinelibrary.

wiley.com/doi/10.11

$11 / j .1365-$

2648.2005.03547.x/

epdf?r3_referer $=$ wol\&

tracking action $=$ prev

iew_click\&show_chec

kout $=1 \&$ purchase_re

ferrer $=w w w . r e a d c u b$

e.com\&purchase_site

license=LICENSE_D

ENIED

Hidayat, A. A. (2013). Kebutuhan Dasar Manusia. Salemba Medika.

Kemenkes RI. (2013).

Riset Kesehatan

Dasar Provinsi Jawa

Timur.

Kurella, M., \& Chertow,

G. M. (2005).

Dialysis Session

Length (" $t$ ") as a Determinant of the A dequacy of Dialysis, 90-95.

https://doi.org/10.1

016/j.semnephrol.20

04.09 .015

Molefe, \& Duma. (2009).

Experiences 
Setiyo Adi Nugroho: Pengalaman Spiritualitas

Batswana women diagnosed with both HIV / AIDS and cervical cancer, Curationis 32 (4): 29-39.

Morton, R. L., Tong, A., Howard, K., Snelling, P., \& Webster, A. C. (2010). The views of patients and carers in treatment decision making for chronic kidney disease: Systematic review and thematic synthesis of qualitative studies. BMJ (Online), 340(7742), 350. https://doi.org/10.1 136/bmj.c112

Patients, H., Preposi, J., Paolo, C., \& Hikmet, C. C. (2016). Religiosity and Health-Related

Quality of Life: A Cross-Sectional

Study on Filipino Christian. Journal of Religion and Health, 55(3), 895-908. https://doi.org/10.1 007/s 10943-0150103-9

Potter, \& Perry. (2005).

Fundamentals

of nursing:

concepts,process, and pratice (6th ed.). philadelphia Mosby. Reig-Ferrer, A., Arenas, M. D., FerrerCascales, R., Fernández-Pascual, M. D., AlbaladejoBlázquez, N., Gil, M. T., \& de la Fuente, V. (2012). Evaluation of spiritual well-being in haemodialysis patients. Nefrologia, 32(6), 731-742. https://doi.org/10.3 265/Nefrologia.pre2 012.Apr.11384

Ruth A. Tanyi, J. S. W. (2003). Adjustment, Spirituality, and Health in Women on Hemodialysis, 12(3).

Retrieved from http://journals.sage pub.com/doi/pdf/10 $.1177 / 10547738032$ 53163

Tarakeshwar Nalini, Pearce Michelle J. \& Sikkema Kathleen J. (2005) Development and implementation of a spiritual coping group intervention 
Setiyo Adi Nugroho: Pengalaman Spiritualitas

for adults living with HIV/AIDS: A pilot study, Mental Health, Religion \& Culture, 8:3, 179190, DOI: $10.1080 / 136946705$ 00138908.

Taylor, E, S., Klein, L. C., Lewis, B. P., Gruenewald, T. L., Gurung, R. A. R., \& Updegraff, J. A. (2000). Biobehavioral Responses to Stress in Females :Fight-orflight, Not, 107(3), 411-429.

https://doi.org/10.1

$037 / / 0033-$

295X.107.3.411

Timmers, L., Thong, M., Dekker, F. W., Boeschoten, E. W., Heijmans, M., Rijken, M. , ... Kaptein, A. (2008). Illness perceptions in dialysis patients and their association with quality of life. Psychology \& Health, 23(6), 679-690. https://doi.org/10.1 080/147683207012 46535

Vitriawan, W. (2007).

Pengalaman pasien pertama kali terdiagnosis HIV/Aids: studi fenomenologi dalam perspektif keperawatan. Thesis FIK UI

1. Wicaksana, I. (2008). Mereka Bilang Aku Sakit Jiwa. Kanisius. Retrieved from https://books.google .co.id/books?id=Ju0 ZRPrCPgUC\&printse $\mathrm{c}=$ frontcover $\& \mathrm{dq}=\mathrm{me}$ reka+bilang+aku+sa kit + jiwa\&hl=en\&sa= X\&ved=0ahUKEwjyy KXcqpjZAhUHso8KH e1GBygQ6AEIKTAA\# $\mathrm{v}=$ onepage $\& \mathrm{q}=$ merek a bilang aku sakit jiwa $\& \mathrm{f}=$ false

Cleary, J. J. D. (2005). Quality of life of patients on haemodialysis for end-stage renal disease. Journal of Advanced Nursing, 51(6), 577-586. Kurella, M., \& Chertow, G. M. (2005). Dialysis Session Length (" $t$ ") as a Determinant of the Adequacy of Dialysis, 90-95.

https://doi.org/10.1016/j. 
semnephrol.2004.09.015 Kusnul, Z., \& Munir, Z. (2012). Efek pemberian jus mentimun terhadap penurunan tekanan darah. PROSIDING Seminar Nasional, 1(2).

Munir, Z. (2019). EFFECT OF LOWERING THE WATERMELON JUICE BLOOD PRESSURE ON HYPERTENSION. Jurnal Ilmiah STIKES Citra Delima Bangka Belitung, 3(2), 10-14.

NUGROHO, S. A. (2016). Studi Fenomenologi: Pengalaman Manajemen Pruritus Pada Klien Hemodialisis di RSUD dr. Mohammad Saleh Probolinggo Tahun 2016. Universitas Muhammadiyah Jakarta. Timmers, L., Thong, M., Dekker, F. W., Boeschoten, E. W., Heijmans, M., Rijken, M., ... Kaptein, A. (2008). Illness perceptions in dialysis patients and their association with quality of life. Psychology \& Health, 23(6), 679-690. https://doi.org/10.1080/1 4768320701246535
Wicaksana, I. (2008). Mereka Bilang Aku Sakit Jiwa. Kanisius. zainal munir;Muhajaroh. (n.d.). Efek Pemberian Jus Semangka Terhadap Penurunan Tekanan Darah. Citra Delima Jurnal Ilmiah, 3(1), 1014. 